\title{
O Avesso da história: relato de viagem em Galvez, Imperador do Acre
}

The other side of the history: travelogue in Galvez, Imperador do Acre

Jeniffer Yara Jesus da SILVA*

Universidade Federal do Pará (UFPA)

RESUMO: Sob o enredo satírico e humorístico, Galvez Imperador do Acre (1976), de Márcio Souza, narra a trajetória de Dom Luiz Galvez Rodrigues no território acreano e utiliza relatos de viagem sobre a Amazônia de forma a subvertê-los, apresentando um novo olhar sobre o povo e costumes pelos locais os quais transita. Por meio do relato de viagem, esta obra identifica uma outra Amazônia, em uma perspectiva crítica sobre a região. Assim, este trabalho analisa a presença e subversão dos paradigmas de relatos de viagem na obra do autor manauara. Para tanto, serão abordados os estudos de Mary Louise Pratt (1999), Flora Süssekind (1990), Maria Juliana da Silva Medina (2003) e Marli Tereza Furtado (2012).

PALAVRAS-CHAVE: Relato de viagem. Ficção amazonense. História e ficção.

ABSTRACT: Under the satirical and humorous plot, Galvez Imperador do Acre (1976), by Márcio Souza, narrates the trajectory of Dom Luiz Galvez Rodrigues in Acrean territory and uses travel reports about the Amazon in order to subvert them, presenting a new look at the people and customs through he places throught. Through the travel narrative, this work identifies another Amazon, in a critical perspective about the region. Thus, this work analyses the presence and subversion of the paradigms of travel accounts in the work of the author manauara. For this purpose, the studies of Mary Louise Pratt (1999), Flora Süssekind (1990), Maria Juliana da Silva Medina (2003) and Marli Tereza Furtado (2012) will be addressed.

KEYWORDS: Travel report. Amazonian fiction. History and fiction.

\footnotetext{
* Mestre em Letras pela Universidade Federal do Pará, Belém - PA. E-mail: jeniffer.yara@gmail.com
}

Revista Moara, n. 56, vol. 1, ago-dez 2020 ISSN: 0104-0944 
Não sou legível, não sou entendivel Sou meu próprio Deus, meu próprio santo, meu próprio poeta Me olhe como uma tela preta, de um único pintor

Só eu posso fazer minha arte Só eu posso me descrever

Vocês não têm esse direito Não sou obrigado a ser o que vocês esperam Somos muito mais! Baco Exu do Blues

O olhar sobre a região Norte e, mais detidamente sobre a Amazônia, foi, há muito tempo, inscrito sob a perspectiva do colonizador. Assim como a América Latina descrita pelos viajantes britânicos de que Mary Louise Pratt trata em Os olhos do Império (1999), a Amazônia e suas regiões também foram definidas por linhas estrangeiras, imbuídas de suas culturas eurocêntricas e suas próprias definições de civilização e sociedade. A partir desse olhar, a Amazônia e seus habitantes foram definidos como bárbaros e selvagens, por um lado, ou como dóceis, cordiais e hospitaleiros, por outro. A região também foi representada ora como inferno verde, ora como paraíso endêmico (FURTADO, 2012) e, assim, a dubiedade sobre essa existência e habitat instaurou-se na Literatura e no imaginário brasileiro, até a chegada de escritores que viriam desmistificar as imagens e discursos construídos pelo estrangeiro viajante.

O relato de viagem, entendido como um gênero híbrido, o qual abarca diferentes paradigmas e convenções narrativas em suas produções, irá servir, neste trabalho, para a compreensão da relação entre história e ficção presente na obra de Márcio Souza. Esta relação também foi analisada por Maria Medina (2013). Em seu trabalho História e Ficção em Galvez Imperador do Acre, Medina analisa sob outro viés que não o das narrativas de viajantes, como proposto aqui:

Galvez imperador do Acre inscreve-se, assim, no terreno da metaficção historiográfica: as aventuras do espanhol, narradas em primeira pessoa, se passam em pleno boom da borracha e vão de novembro de 1897 , quando contava 39 anos, até o limiar da virada do século, em dezembro de 1899, com recuos no tempo, em que relata suas peripécias da juventude. Estão divididas em quatro partes: "1. Novembro de 1897 a Novembro de 1898"; "2. Em Pleno Rio Amazonas”; “3. Manaus, Março/Junho 1899”; e "4. O Império do Acre Julho - Dezembro de 1899", cada uma delas introduzida por uma espécie de epígrafe, em que são citados, respectivamente, Miguel de Cervantes, Calderón de La Barca, o próprio Galvez e Lope de Vega. Não há como deixar de reparar na fina ironia do narrador, ao inserir seu herói junto da melhor tradição canônica espanhola dos séculos XVI e XVII, uma forma de atribuir relevância às suas aventuras (MEDINA, 2013, p. 122)

Revista Moara, n. 56, vol. 1, ago-dez 2020 ISSN: 0104-0944 
Não há como negar a presença de traços do romance histórico ${ }^{1}$ contido na produção do autor manauara, como o distanciamento entre acontecimentos históricos presente na narrativa, a temporalidade cronológica e a narração em terceira pessoa, em simulação a um distanciamento e imparcialidade pretendia (BAUMGARTEN, 2000, p. 170), porém, para além das atribuições históricas inseridas em seu enredo, atreladas a documentos e fatos ocorridos no espaço e tempo de sua produção, as semelhanças com as convenções de escrita presentes nos relatos de viagem, analisadas por Pratt (1999) e Süssekind (1990) podem ser demonstradas pelas mesmas pistas que Medina percorre.

$\mathrm{O}$ relato de viagem abrange diferentes paradigmas de narrativas. No que tange à prosa manauara aqui analisada, as evidências estão na retomada de elementos dos escritos cientificistas/naturalistas, os quais mantinham descrições minuciosas sobre os lugares que passavam, subvertidos na prosa satírica de Márcio Souza. Também está presente o relato de sobrevivência, escrito em primeira pessoa, em que o viajante supera determinados obstáculos em sua trajetória, seja pela "natureza inimiga" ou pelos povos selvagens com que se encontra, heroicizando o personagem nos percalços que supera, este que também se encontra alterado no romance amazônida. Tendo isso em vista, descreveremos de que forma essas convenções se encontram em Galvez imperador do Acre, à luz dos trajetos percorridos por Flora Süssekind (1990) ao analisar a prosa ficcional brasileira inspirada nos relatos de viagem.

A narrativa ambienta-se na passagem do século XIX para o XX e conta a trajetória do viajante espanhol Luiz Galvez, por meio de um narrador que alega ter encontrado o documento com os feitos considerados históricos, portanto, reais. Tal estratégia intenta inscrever o romance como fidedigno, permeado de referências e passagens que comprovariam sua veracidade.

As memórias do fidalgo espanhol, escritas em português em 1945, com o herói já octogenário, teriam sido encontradas acondicionadas numa pasta de cartão num sebo do Boulevard Saint Michel e compradas pelo narrador, "um turista brasileiro que andava fuçando as livrarias de Paris" (SOUZA, 2001, p. 14)

\footnotetext{
1 SILVA JÚNIOR, Renato Otero da. Galvez Imperador do Acre: O discurso do romance e a ficcionalização da história. 2006. 105 f. Dissertação (Mestrado) - Curso de Letras, Fundação Universidade do Rio Grande, Rio Grande, 2006. Disponível em: $<$ http://repositorio.furg.br/bitstream/handle/1/2652/renatootero.pdf?sequence=1>. Acesso em: $21 \mathrm{dez}$. 2018.
}

Revista Moara, n. 56, vol. 1, ago-dez 2020 ISSN: 0104-0944 
O recurso ao manuscrito é utilizado também em relatos de viagem e em outras produções ficcionais, como a de José de Alencar, em $O$ Guarani, de que Süssekind (1990, p. 49) trata. A confiabilidade da narrativa repousa, neste caso, na trajetória do viajante espanhol e no manuscrito "encontrado" pelas ruas de Paris.

O que parece dar confiabilidade a essas impressões e notas é, de um lado, a própria experiência da viagem, de outro, o fato de se tratar de um "olhar estrangeiro". De se tratar de alguém de fora, mas que de fato teria testemunhado o que narra (Süssekind, 1990, p. 49).

Contudo, em Galvez, o narrador não é testemunha, mas ainda assim intervém na trama a título de dar mostras do que de fato teria ocorrido. Desse modo, a dubiedade sobre o real e o ficcional permanece até o final da narrativa.

Para além dessa estratégia, a narrativa de Márcio Souza aborda fatos históricos ocorridos, apresentando o território em que se situam as cenas e aventuras de Luiz Galvez, bem como descrições sobre clima, hábitos e povo, em digressões inseridas entre os capítulos do romance. Logo após o narrador apresentar-se para explicar como fora encontrado o manuscrito que publica, insere a descrição das origens do Acre, no capítulo intitulado Folha de rosto:

\begin{abstract}
A tinta já anda meio desbotada por aqui e algumas traças se locupletaram em alguns adjetivos, mas a história começa falando sobre um triângulo de terras que pertencia aos índios amoaca, arara, canamari e ipuriná. Parece que nos mapas bolivianos daquela época o triângulo estava assinalado como tierras no descubiertas. [...] Os ipuriná chamavam aquele rio de Aquiri. O cearense, pouco afeito à arte da caligrafia, rabiscou este nome no envelope, que o visconde, depois de muito trabalho, decifrou como ACRE. O visconde começava a fazer um bom negócio sem saber que batizara também um território. O ACRE era rico de belos espécimes de hevea-brasiliensis e viveria por muitos anos sob o signo dos equívocos (SOUZA, 2001, p. 15).
\end{abstract}

A inserção de excertos explicativos sobre a história local, em momentos esparsos da narrativa, desloca o foco da trama e intenta, ao mesmo tempo, confirmar a veracidade dos fatos ocorridos, além de "fundar uma geografia e uma paisagem singulares e descrever acidentes, cenários e tipos peculiares" (Süssekind, 1990, p. 61). No entanto, diferente dos primeiros escritores descritos pela autora citada, que viriam confirmar paisagens e costumes locais idealizados pelos estrangeiros viajantes, o

Revista Moara, n. 56, vol. 1, ago-dez 2020 ISSN: 0104-0944 
narrador de Galvez mescla as descrições científicas com cenas de ações trágicas ou cômicas, como a do trecho acima, em que o nome de um território é definido em virtude do erro de leitura de uma caligrafia ruim, iniciando uma história permeada de equívocos em cenas de tom humorístico.

As cenas tragicômicas são presenciadas em outros momentos de descrições sobre o espaço:

O território do Acre fica a $9^{\circ}$ Sul de latitude e $70^{\circ}$ Oeste de longitude. Naquela tarde um grupo de seringueiros estava de folga, na propriedade denominada Bela Vista, de Ubaldino Meireles. [...] Os seringueiros fariam a festa no terreiro do barracão central e estavam capinando a área desde a madrugada. Dois seringueiros tocavam viola na escada do barracão, ensaiando algumas músicas. Na frente do barracão tremulava uma bandeira brasileira e os dois músicos tocavam um chorinho. No outro dia o capataz estaria arrependido e não saberia explicar ao coronel Ubaldino a morte de dois homens. Eles haviam sido trucidados a golpes de terçado no auge da bebedeira que era sempre o melhor da festa (SOUZA, 2001, p. 42).

A descrição acima revela o tom satírico ${ }^{2}$ empreendido em toda a trama de Márcio Souza, circunscrevendo uma narrativa que apresenta o território, seu povo, juntamente a seus traumas, sua violência e cenas impudicas vivenciadas pelo protagonista e seus companheiros. A narrativa de "sobrevivência" de Luiz Galvez é permeada por aventuras mirabolantes, não mais sob o signo de uma natureza selvagem, inimiga do viajante, mas de enrascadas em esquemas de traições e atos ligados à vida boêmia do protagonista.

Nas cenas seguintes, ao precisar roubar o documento que comprovaria a venda do Acre para uma Corporação Internacional americana, o narrador antecede o ato com passagens sobre a amante de Galvez, permeando a narrativa com trechos eróticos:

\begin{abstract}
A lua começava a chegar na linha do horizonte entre silhuetas de esguios açaizeiros e estávamos deitados na grama. No quintal da casa de Cira. O marido dormia lá em cima e eu ia roubar um documento. As janelas apagadas da imensa casa e a textura dos cabelos de Cira espalhados na grama. Era difícil escapar ao destino de aventureiro. (Eros e Látex, SOUZA, 2001, p. $50)$.
\end{abstract}

Posteriormente, no capítulo intitulado Roubo, descreve a cena rocambolesca:

\footnotetext{
${ }^{2}$ Para estudos sobre a sátira no romance, consultar: Machado, Janete Gaspar. "Galvez, o imperador do Acre": a sátira da história. Travessia 2, 1981.
}

Revista Moara, n. 56, vol. 1, ago-dez 2020 ISSN: 0104-0944 
Meia-noite. Entrei na casa de Trucco com um lenço azul no rosto. O mordomo acordou e ameacei-o com uma pistola. Trucco veio ver o que era, de robe-de-chambre. A cara amarrotada de sono, e pedi o documento com a voz americana. Ele não reagiu e me passou o envelope azul. Examinei, era o que eu queria. Fugi soltando uma gargalhada pavorosa. (SOUZA, 2001, p. 53).

Interessante observar os capítulos curtos presentes no romance, um prelúdio à Oswald de Andrade em seu Memórias Sentimentais de João Miramar ${ }^{3}$, mas que também rememora a produção folhetinesca a qual o próprio narrador insere sua publicação. No entanto, de acordo com Medina (2013, p. 123-124), o escrito assemelhase muito mais às produções picarescas, devido aos traços característicos desse gênero, como a autobiografia, os episódios de aprendizagem, a ascendência e decadência do personagem ao final da trama. Porém, o discurso subjetivo, as peripécias contadas, a história em retrospectiva que intenta ser verídica, rememora também os paradigmas analisados por Mary Louise Pratt nos relatos de sobrevivência. Assim, a veracidade das aventuras contadas pelo personagem é confirmada por este participar delas e inserir, também, as passagens descritivas e históricas dos espaços que percorre e da comunidade de homens que convive em determinados estados pelos quais transita.

Contudo, diferentemente dos viajantes analisados por Pratt, desejosos em convencer seus leitores, algumas cenas que teriam sido escritas pelo próprio Luiz Galvez são desmentidas pelo narrador. Após descrever como teria furtado o documento, o narrador desmente as cenas fabulosas descritas pelo protagonista:

Perdão, leitores! Neste momento sou obrigado a intervir, coisa que farei a cada momento em que o nosso herói faltar com a verdade dos fatos. É claro que ele conseguiu o documento. Mas da maneira mais prosaica do mundo. Naquele dia Luiz Galvez foi a um restaurante do Largo da Pólvora e comeu um frango tostado. $\mathrm{O}$ restaurante estava vazio e havia algumas cocottes sonolentas conservando com garçons desocupados. Luiz Galvez saiu irritado com o serviço do restaurante. Tomou um fiacre e rumou para a casa de Trucco onde se deixou cair na poltrona do gabinete do cônsul. Estava um calor insuportável e nuvens negras comprimiam as pessoas. Trucco estava se abanando com um lenço, olhando a janela. Os dois suplicavam por uma corrente de ar. Trucco pegou um papel e começou a ler, a testa gotejando. A luz era medíocre, e a chuva começou a molhar lá fora. Trucco pediu a Luiz Galvez que ele traduzisse o documento. Não confiava em outra pessoa para fazer este trabalho (SOUZA, 2001, p. 53).

\footnotetext{
3 SAKAI, Luiz Guilherme Fernandes da Costa; ALMEIDA, Geruza Zelnys de. O cine-folhetim em Galvez, imperador do Acre, de Márcio Souza. Todas As Musas, São Paulo, v. 2, n. 01, p.137-149, 2010. Disponível em: <https://www.todasasmusas.org/02_01.htm>. Acesso em: 21 dez. 2018.
}

Revista Moara, n. 56, vol. 1, ago-dez 2020 ISSN: 0104-0944 
A quebra da expectativa é nítida e ao desmentir o que o protagonista relata, o narrador envolve o leitor na desconfiança sobre ser ou não o escrito fidedigno. Além disso, a interrupção também demonstra outra estratégia folhetinesca, em dirigir-se ao leitor, como em uma conversa pessoal, para explicar algum fato durante a narração.

A interrupção também descreve as ações de Galvez com o clima do local, caracterizado pelo calor e pelo repentino precipitar de uma chuva já esperada ao ver o céu antes negro. Essa descrição climática, identificável em todo o período do ano nas regiões do Norte, precisaria ser explicada ou pelo menos apresentada a leitores que desconhecem esse tipo de clima. A ambientação da região é clara, enfatizada não apenas pelos repentinos excertos de descrições históricas e científicas inseridas no decorrer da narrativa, mas também apresentadas nos costumes e hábitos locais descritos.

Em todo o romance, sempre é enfatizado que a narrativa trata das peripécias ${ }^{4}$ decorridas das viagens realizadas pelo protagonista, seja primeiramente descrevendo a cidade onde se encontra nos momentos de cenas anteriores ao local para onde Galvez irá se deslocar, seja na descrição dos percursos que irá fazer, como a passagem da parte 1 para a parte 2 do livro, em que Luis Galvez desloca-se pelo rio Amazonas de Belém para Manaus:

\begin{abstract}
Nesta segunda parte da história o nosso herói, subindo o rio Amazonas, percorre as quase novecentas milhas que separam Belém de Manaus. Existem na região 218 espécies de mosquitos classificadas pelos cientistas (SOUZA, 2001, p. 77).
\end{abstract}

A identificação da mudança de cenário ocorre junto a breves inserções de informações cartográficas, como que reafirmando as descrições contidas em relatos sobre a Amazônia, tais como a de Charles Marie de La Condamine em seu Viagem na América Meridional descendo o rio das Amazonas (1759). As informações de latitude, longitude, temperatura e animais pertencentes à região, intercaladas por pequenas ações, narradas em primeira pessoa, e os percalços superados pelo viajante, remontam sempre

\footnotetext{
${ }^{4}$ Em Poética, Aristóteles define peripécia como mudança de acontecimento para outro contrário, distinguindo-a como reviravoltas ocorridas, de maneira verossímil ou necessária para a condução do enredo, conduzindo à compaixão ou ao pavor, presente tanto na mimesis trágica quanto cômica. Em Galvez, Imperador do Acre, no presente artigo, não enfatizaremos o romance como uma narrativa de peripécias, pois o foco volta-se para a relação direta entre as estratégias narrativas da prosa de ficção para com as estratégias narrativas dos relatos de viagem.
}

Revista Moara, n. 56, vol. 1, ago-dez 2020 ISSN: 0104-0944 
à trajetória do protagonista, sobrevivente então das peripécias que enfrenta, em meio às paisagens, homens e mulheres com os quais convive:

Largaram-me numa praia deserta do rio Amazonas. A aventura começa agora. Andei pela praia quanto o vapor eclesiástico se distanciava. Tirei sapatos e arregacei as calças, fui chutando a água. Andava sem direção e me espantei com a imensidão da água amarela (SOUZA, 2001, p. 85).

O tom dramático por ser deixado em uma terra completamente desconhecida não é presente na perspectiva de Galvez, mas sim uma certa "descontração" quanto ao local e situação em que se encontra.

O estilo de composição em uma narrativa como as de viajantes que viriam inscrever uma paisagem "só natureza", desencarnada das histórias dos povos que a habitavam também se faz presente na prosa do personagem, mas em tom irônico:

\footnotetext{
Estou prisioneiro de uma paisagem. A praia era a terra de ninguém, e comecei a pensar no desafio que aquela paisagem devia representar para a literatura. Ora vejam como eu era civilizado! Eu estava abandonado na selva e pensava em problemas literários. Problemas que, por sinal, ainda não consegui superar. Sei apenas que a preocupação com a natureza elimina a personagem humana (SOUZA, 2001, p. 85).
}

A trama é ambientada no final do século XIX, com o fim do auge do período da borracha e, diferente das descrições de La Condamine, em que o viajante ressalta a importância do látex e a riqueza que traria para a região se bem utilizada e comercializada, o narrador de Galvez textualiza, mesmo que indiretamente, o cenário prejudicial que essa exploração trouxe aos homens da região:

\footnotetext{
Você vem em busca de riqueza, meu anjo (ela costumava me chamar de meu anjo). E por aqui só se ganha dinheiro na seringa. Eu queria te ver com uma machadinha dando golpes no tronco de uma seringueira. Se endividando no barracão central. Uma figura clássica da sociologia amazônica (SOUZA, 2001, p. 49).
}

As associações com o relato de viagem não se esgotam nas referências semelhantes ao estilo de narrar dos cronistas. O ponto de intersecção entre o relato de viagem e a prosa de ficção de Márcio Souza também se encontra na citação de viajantes, sejam eles reais ou fictícios, bem como na parodização de um personagem, descrito 
como um cientista viajante, e sua mirabolante teoria sobre a construção do teatro de Manaus.

No capítulo Segunda Conferência, ao descrever as ideias de Sir Henry Lust, uma das personagens do enredo, são citados Louis e Elizabeth Agassiz, exemplificando quem eram e o que produziam esses viajantes em terras brasileiras, além de mencionar La Condamine no capítulo Constatação, já referenciado anteriormente. De forma irônica, é relatada a surpresa do viajante La Condamine ao presenciar uma cena de índios cambeba em um jogo de bola. $\mathrm{O}$ viajante francês foi o primeiro a percorrer o curso do Amazonas, realizando um estudo que viria ser parâmetro de viagens naturalistas/cientificistas.

O primeiro cientista a estudar a hevear-brasiliensis, o francês Charles Marie de La Condamine, observando um jogo de bola entre os índios cambeba, pensou que a borracha desafiava a lei da gravidade da terra (SOUZA, 2001, p. 38).

Os viajantes fictícios são também rememorados em Galvez, como nos capítulos intitulados Julio Verne, Phileas Fogg, personagem de $A$ volta ao mundo em 80 dias, e Gulliver. No primeiro capítulo citado, novamente percebe-se a subversão, agora sobre a aventura do viajante:

Eu estava com os fundilhos molhados de água e vi que a condição de aventureiro é quase sempre desconfortável. O aventureiro vive como se tivesse em fim de carreira. Não existe marasmo e os contratempos estão sempre escamoteados das histórias de aventura. Pois digo aos leitores que ninguém passa mais baixo que o aventureiro. Quem me dera fosse eu um Phileas Fogg na calha do rio Amazonas fazendo a volta ao mundo em oitenta seringueiras (SOUZA, 2001, P. 87).

No capítulo intitulado Gulliver, após ter sido abandonado em terras desconhecidas, o aventureiro espanhol retrata a prisão dos religiosos, seus companheiros anteriores na embarcação que fora expulso, pelos "selvagens" da terra onde se encontra, revelando a brutalidade no ato antropofágico que cometem, e o medo do próprio personagem. Cenas que relembram a captura do personagem de Jonathan Swift ao ser defrontado pelo povo de Liliput, porém, em Galvez, insere-se a antropofagia dos povos indígenas, descritas nas primeiras crônicas sobre essas comunidades como ato imoral e de crueldade inimaginável.

Revista Moara, n. 56, vol. 1, ago-dez 2020 ISSN: 0104-0944 
No entanto, no capítulo subsequente, Etnógrafo, é revelada a sensação de Galvez ao sentir o cheiro dos corpos assados; o que geraria repulsa, transformou-se em fome:

\begin{abstract}
Os ingás não me haviam enchido o estômago e aquele odo adocicado era tentador. Não quero chocar ninguém e não sei se participaria do banquete, se convidado, mas que a fome era forte, isso não duvidem. O suor escorria pelo meu sovaco (SOUZA, 2001, p. 89).
\end{abstract}

Em seguida, novamente tem-se a interrupção do narrador, negando os fatos descritos anteriormente e, logo o viajante parodiado em Galvez, Sir Henry Lust, é apresentado. Descrito como "grande naturalista e gastrônomo", possuindo "porte baixo" e "bigode louro de oficial britânico", o britânico expõe sua teoria de que o Teatro Amazonas seria, na verdade, criação de extraterrestres:

Sir Henry Lust estava na Amazônia com a permissão do governo brasileiro e por sua própria conta. Era um homem rico, apesar de seus vinte e outo anos. Sir Henry fundara em Bombaim a British Society for Primitive Metaphysical Research e era engenheiro. Falava na terceira pessoa do plural e recebera a Ordem da Águia Branca de dis-Abeba. Era um desses pioneiros que percorriam a Amazônia em nome da ciência. Deglutindo os fofos biscoitos, Sir Henry me ofereceu suas teses reveladoras. "Quando lhe disserem Manaus", grunhiu Sir Henry, "que o Teatro Amazonas é obra de um obscuro governador, não acredite. Isso é fruto da ignorância dos nativos. Estamos certos, Mister Aria, que os extraterrestres existem e que o Teatro Amazonas é uma de suas marcas. A concepção de que o Teatro Amazonas é um artefato espacial é exclusivamente racional, isto é, a intervenção no meio da jungle equatorial é produto de seres inteligentes, mais poderosos que nós, seres materiais, habitantes do espaço exterior". Sir Henry acabou a frase apontando um dedo branco e encardido de fumo para o céu azul. Os vinhos de Sir Henry eram dignos de extraterrestres (SOUZA, 2001, p. 95).

A teoria do viajante seria mais uma das subversões da história inscritas na prosa de Márcio Souza. A ideia é de que uma construção como essa, europeia, em meio a Amazônia, local incivilizado, habitado por "selvagens recentemente tirados de sua floresta” (LA CONDAMINE, 2000, p. 74), só poderia ser obra de alienígenas:

Sir Henry não concebia que o Teatro Amazonas fosse obra de seres humanos. Muito menos dos semicivilizados nativos, notórios por sua inferioridade racial e total falta de capacidade para o raciocínio lógico (SOUZA, 2001, p. 95).

O surgimento da ironia sobre o viajante europeu e sua incrível teoria extraterrestre "se dá sob o signo da dominação" (SANTOS, 2011, p. 128) e possui direta relação com

Revista Moara, n. 56, vol. 1, ago-dez 2020 ISSN: 0104-0944 
as declarações sobre os povos nativos das Américas colonizadas. Como Pratt (1999) elucida, o olhar do europeu estava armado para com as populações e lugares que se deparariam esses viajantes. Este olhar armado, carregado de suas próprias culturas, normas e condutas sociais, viria a reproduzir discursos preconceituosos e de estranhamento para com o outro, completamente avesso ao que era comum ao viajante, seriam povos necessitados "por enquanto senão de fazer deles uns homens, o que não é pequeno trabalho" (LA CONDAMINE, 2000, p. 74).

Francisco Ewerton Almeida Santos (2011) também trata da relação de Galvez imperador do Acre com Macunaíma (1928), de Mário de Andrade, e nos diferentes tópicos que levanta acerca dessa associação, revela o caráter crítico da parodização nesse personagem:

\begin{abstract}
Da mesma forma, a teoria de Henry Lust, apesar de parecer, à primeira vista, um grande despropósito, pode ser lida como uma bem humorada forma de denunciar o caráter postiço dos signos de civilização, encontrados em meio à selva. O termo "alienígena" usado pelo cientista em sentido interplanetário pode ser compreendido como uma metáfora da importação de valores e costumes europeus, bens simbólicos primeiramente impostos pelo colonizados, e agora comprados pelo novo rico da borracha sob a insígnia de status. Os modelos de civilização, os ideais de progresso, o glamour e a riqueza, apresentam-se em descompasso com a miséria e o caráter capenga que as instituições ocidentais, transplantadas sem rigor crítico por uma elite ainda mentalmente colonizada e ideologicamente inconsistentes, adquirem no contexto dos trópicos (SANTOS, 2011, p. 129).
\end{abstract}

A estranheza de tal construção em meio a selva amazônica é emblemática sobre os costumes, roupas e, nesse caso, construções europeias em paisagens locais, corpos estranhos em paisagens ainda a explorar. Dessa forma, a construção do grande monumento é atribuída a extraterrestres e não aos homens da região, meramente incivilizados.

Em se tratando dos contatos realizados entre estrangeiros e nativos, o romance também alude à demonstração de costumes dos locais por onde Luiz Galvez passa, em uma tentativa possível de explicitar os hábitos daqueles povos com os quais o personagem principal se deparava:

\footnotetext{
Não entendam mal uma terra pela vida dissipada de um aventureiro. Em três meses de Amazonas minha experiência foi praticamente dominada pelos favores da boêmia noturna. Não há muitas opções numa cidade de vinte mil almas onde um ovo de galinha custa quinze mil-réis e assim mesmo há dinheiro para comprar ovos para as omeletes. E os ovos são importados.
}

Revista Moara, n. 56, vol. 1, ago-dez 2020 ISSN: 0104-0944 
Numa cidade assim, é natural que o amor mercenário e a moral burguesa entrem em disputa, ambos saindo com arranhões maliciosos. Nenhum homem se contentava com a vida de família. Estavam no século XIX, mas padeciam de preconceitos do século XVI. Todos divididos e ávidos [...] (SOUZA, Amazonas Pitoresco, 2001, p. 129).

Nesse caso, novamente percebe-se o olhar satírico do personagem viajante descrevendo cenas que não encontraríamos facilmente nos relatos de viagem, circunscrevendo uma burguesia atrelada a valores morais, mas hipócrita e impudica, como é descrita nas passagens seguintes desse capítulo:

\begin{abstract}
O major Freire era casado com uma gentil senhora, neta de um governador do estado. Conheci esta infeliz senhora numa recepção oficial. Era bonita, semialfabetizada e mal-informada, passada os dias encerrada em sua casa, bordando e lendo romances idiotas. Ela não sabia que era infeliz, pensava que tinha uma moléstia grave. O major Freire não permitia que ela saísse desacompanhada e devia fazer amor uma vez por ano. A prova é que estavam casados há oito anos e tinham sete filhos. E o major Freire também o mais conhecido libertino de Manaus. O sexo obrigava o dinheiro a ser criativo (SOUZA, 2001, p. 129).
\end{abstract}

Ao atentarmos para a moral apresentada no capítulo, esta é completamente afrontada pela narrativa, e, diferente das crônicas de costumes citadas por Süssekind (1990), as quais mantinham em suas publicações um intento não só de apresentar diferentes regiões e populações ao restante do Brasil, mas também de conduzir seu público leitor a ações de boas condutas ou apresentar-lhes maus exemplos para não serem seguidos, Galvez desafia essa lógica, ao conter cenas e personagens tão atípicos para um cenário predominantemente conservador naquele período.

Distante do narrador de costumes moralizante, mas próximo da novela picaresca de que trata Flora Süssekind, Galvez imperador do Acre inscreve "uma outra paisagem" (SÜSSEKIND, 1990, p. 250) da Amazônia por meio de sua narrativa jocosa e crítica, dialogando diretamente com os relatos de viagem, criadores de todo um imaginário de uma natureza só paisagem, de selvagens incivilizados e terras férteis a explorar.

Na trama de Márcio Souza, o protagonista morre de velhice, ao final de tudo, depois de ser derrotado pelos seringalistas cansados de seu governo, muito mais preocupado com vinhos e festas, do que com os "reais" problemas da região. Dessa forma, “[...] se desfaz parte do encantamento que costuma produzir as narrativas 
maravilhadas ou misteriosas de viagens e da glorificação, por tabela, de seus protagonistas" (Süssekind, 1990, p. 262).

\section{Considerações finais}

Como parte integrante de produções que se relacionaram com os viajantes europeus, em uma clara tentativa de fundar um corpus identitário sobre a Amazônia, Galvez imperador do Acre também incorpora os topoi ou mesmo convenções narrativas do relato de viagem, porém, subvertendo tais paradigmas, em um tom picaresco e satírico, delineando novas imagens sobre o homem e o espaço regional nortista.

A “descolonização de ideias" sobre a região amazônica na prosa de ficção de Márcio Souza ocorre por meio da linguagem irônica e paródica, característico do período ao qual lhe atribuem participação, ao lado de Oswald e Mário de Andrade. Também, por meio da inserção dos paradigmas de relatos de viagens, ao absorvê-los em sua trama, mas utilizando-os à sua maneira, em um movimento de contraponto e insubmissão quanto às ideias emblemáticas sobre o povo e a região amazônida inscrita no imaginário popular e erudito.

A história inscrita por Márcio Souza em Galvez é muito mais uma produção crítica e satírica sobre nossa História, nossa língua e nossos costumes, estes que foram demarcados com a limitação ideológica do olhar estrangeiro, mas que podem e devem ser esmaecidos por nossas próprias marcações, nossos próprios registros e tramas, sob o olhar de outro, agora não mais estranho a essa terra, mas pertencente a ela, descortinando sua própria identidade.

Revista Moara, n. 56, vol. 1, ago-dez 2020 ISSN: 0104-0944 


\section{REFERÊNCIAS}

BAUMGARTEN, Carlos Alexandre. O novo romance histórico brasileiro. Via Atlântica, n. 4, 2000.

FURTADO, Marlí. A Amazônia em narrativas (1914/1934): um tributo a Euclides da Cunha e aos viajantes. In: NUÑEZ, Carlinda F. P.; SALES, Germana et al (Org.). História da Literatura: práticas analíticas, volume II. Rio de Janeiro: Ed. Makunaima, 2012.

LA CONDAMINE, Charles-Marie de. Viagem na América Meridional descendo o rio das Amazonas. Brasília: Senado Federal, 2000.

MEDINA, Maria Juliana da Silva. História e Ficção em Galvez Imperador do Acre, De Márcio Souza. Interdisciplinar - Revista de Estudos em Língua e Literatura, v. 19, 2013.

PRATT, Mary Louise. Os olhos do império: relatos de viagem e transculturação. Bauru, SP: Edusc, 1999.

SANTOS, Francisco Ewerton Almeida. Colagem, antropofagia e subversão em Galvez, imperador do Acre, de Márcio Souza. 2011. 161 f. Dissertação (Mestrado) Curso de Letras, Universidade Federal do Pará, Belém, 2011. Disponível em: <http://repositorio.ufpa.br:8080/jspui/bitstream/2011/2772/1/Dissertacao_ColagensAntr opofagiaSubversao.pdf>. Acesso em: 26 dez. 2018.

SOUZA, Márcio. Galvez imperador do Acre. Rio de Janeiro: Record, 18ª ed., 2001.

SÜSSEKIND, Flora. O Brasil não é longe daqui: o narrador, a viagem. São Paulo: Companhia das Letras, 1990.

Revista Moara, n. 56, vol. 1, ago-dez 2020 ISSN: 0104-0944 